\title{
Computational Studies of End-Wall Flame Quenching at Low Pressure: The Effects of Heterogeneous Radical Recombination and Crevices
}

\author{
THOMPSON M. SLOANE \\ Physical Chemistry Department General Motors Research Laboratories Warren. MI +8090 \\ and \\ ANDREW Y. SCHOENE \\ Mathematics Department University of Michigan Dearborn. MI
}

\begin{abstract}
A computational study of the effect of heterogeneous radical destruction and crevices on end-wall flame quenching in a lean $\mathrm{CH}_{4}-\mathrm{O}_{2}-\mathrm{Ar}$ mixture at low pressure has been performed. The unsteady conservation equations for a chemically reacting multicomponent gas have been solved with the commercially available partial differential equation solver package PDEPACK. Heterogeneous radical destruction at a cooled surface was found to have a minor effect on flame quenching compared to homogeneous destruction in the cooled tlame gases near the surface. These results are in qualitative agreement with experiments performed in a side-wall geometry. Cooled crevices, however, had a much greater effect on the postquench oxidation of the fuel. Whereas the fuel layer left after quenching near a tlat wall burns up more rapidly as the pressure is increased, unbumed fuel left in a crevice after quenching burns up more slowly as the pressure is increased. This reaftirms the potential importance of crevices as sources of unburmed hydrocarbons in an engine.
\end{abstract}

\section{INTRODUCTION}

Combustion calculations which involve solving the unsteady conservation equations with a detailed chemical kinetics model have been used with considerable success in advancing our understanding of combustion processes [1-3]. Tested chemical models now exist for combustion of methanol [4], $\mathrm{CH}_{4}$ [4], methane-ethane mixtures [5], $\mathrm{CO}$ [6], and $\mathrm{H}_{2}$ [6]. Potential applications for these calculations are numerous and are well described in a recent review [3]. We have begun to develop a code to perform these calculations because of their usefulness for conducting computer experiments on such combustion phenomena as flame quenching, propagation, inhibition, ignition, and pollutant formation and destruction.

Copyright (C) 1983 by The Combustion Institute

Published by Elsevier Science Publishing Co., Inc.,

52 Vanderbilt Avenue, New York, NY 10017
These calculations should help us understand at least in a qualitative way laboratory experiments we perform on combustion phenomena. They should also provide a rational and efficient basis for suggesting further experimental work.

The first problem we have chosen for study is the flame-quenching problem in a mixture of methane, oxygen, and argon. This phenomenon has interested us for a long time, and has recently been the subject of a number of experimental and computational studies. Recent experimental work [7] has indicated that laminar end-wall quenching by a clean, cooled surface may not be nearly as important a contributor to hydrocarbon emissions from automobile engines as once thought. In simple systems it has been shown $[8,9]$ that the fuel is completely consumed in a flame burning near a cooled surface. The computational study of

$0010-2180 / 83 / 01109+14503.00$ 
Westbrook et al. [10] and in-cylinder sampling measurements [11] have confirmed these results. However, three other possible sources of hydrocarbon emissions have been identified by various laboratories. It has been shown that by reducing or eliminating crevices in a combustion bomb [12] or an engine [13], the unburned hydrocarbons can be reduced significantly. An oil film on the surface of a combustion bomb has also been identified as a source of residual hydrocarbons [14]; this phenomenon has been investigated by mathematical modeling [15]. In addition, there is the question of how turbulence might affect flat-wall quenching. There is no direct evidence as to how turbulence might affect wall quenching, but we can speculate that turbulence might increase the quench layer thickness. It might also increase the rate of transport of fuel away from the surface and radicals toward the surface, resulting in fast oxidation of quench layer hydrocarbons. How turbulence affects flatwall flame quenching is an interesting area for future research.

Our aim in the work reported here is twofold. The first goal is to determine the importance to flame lquenching of homogeneous destruction of radicals compared to heterogeneous destruction. The latter might be possible on the surface of engine deposits, whose mode of chemical interaction with the flame is unknown. Complete radical destruction at the surface represents the maximum chemical effect which could contribute to flame quenching. The second goal is to approximate the effect of a crevice at the surface and to compare the rate of fuel disappearance with the rate found for flat-wall quenching.

Our previous experimental paper [8] describes experiments we have performed to determine the relative effect of cooled catalytic and noncatalytic surfaces on quenching a $\mathrm{CH}_{4}-\mathrm{O}_{2}-\mathrm{Ar}$ flame in a side-wall geometry at constant pressure. The calculations reported here involve a comparison of the effectiveness of catalytic with that of noncatalytic cooled surfaces on end-wall quenching at constant volume. Although the physical arrangement is different, there are some similarities in the chemistry involved, and the calculations will aid us in interpreting the ways in which chemical changes which we observed in the gas near the quenching surface are departures from the chemistry of a free-burning flame.

We first discuss our numerical model, which is similar to that used previously [10] except for the boundary conditions, which allow radical destruction at the quenching surface and modification of the energy equation to simulate the presence of a crevice. We then discuss the method of solution of the equations with the commercially available partial differential equations solver package PDEPACK. Flame speed calculations are used to test the reliability of the equation solution method. Results and discussion will then be presented for calculations on a lean $\mathrm{CH}_{4}-\mathrm{O}_{2}$ - $\mathrm{Ar}$ mixture burning at constant volume. We compare heterogeneous and homogeneous radical destruction and show that heterogeneous destruction is much less important than homogeneous destruction near a cooled surface under the conditions of our calculations. A discussion of the similarities between these calculations and our experiments is included. We then demonstrate the drastic effect on the fuel disappearance rate due to the presence of a cooled crevice.

\section{MATHEMATICAL MODEL}

The equations to be solved are the equations for conservation of mass, momentum, and energy in a chemically reacting gas. These equations can be found, for example, in Hirschfelder et al. [16]. Their derivation and the approximations made to obtain the equations are well described there. The equations used are the following:

$$
\frac{\partial \rho}{\partial t}+\frac{\partial}{\partial x}(\rho \nu)=0
$$

where $\rho$ is the mass density and $\nu$ is the flow velocity;

$$
\frac{\partial C_{i}}{\partial t}=\frac{-\partial}{\partial x}\left(C_{i} \nu\right)+\frac{\partial}{\partial x}\left[C D_{i} \frac{\partial}{\partial x}\left(\frac{C_{i}}{C}\right)\right]+K_{i}
$$


where $C_{i}$ is the concentration of component $i$, $D_{i}$ is the diffusion coefficient for component $i$, $C$ is the total concentration, and $K_{i}$ is the net rate of production of component $i$ due to chemical reaction (We have assumed in this expression that $\rho / M_{\mathrm{Ar}} \approx C$, where $M_{\mathrm{Ar}}$ is the molecular weight of argon);

$$
\frac{\partial \nu}{\partial t}=-\nu \frac{\partial \nu}{\partial x}-\frac{R}{\rho} \frac{\partial}{\partial x}(C T)+\frac{1}{\rho} \frac{\partial}{\partial x}\left(\eta \frac{\partial \nu}{\partial x}\right),
$$

where $R$ is the gas constant, $T$ is the temperature, and $\eta$ is the coefficient of viscosity;

$$
\begin{aligned}
\frac{\partial T}{\partial t}= & -\nu \frac{\partial T}{\partial x}+\frac{1}{C_{v}}\left\{\frac{\partial}{\partial x}\left(\lambda \frac{\partial T}{\partial x}\right)-\operatorname{CRT} \frac{\partial \nu}{\partial x}\right. \\
& -\sum_{i} \epsilon_{i} \frac{\partial}{\partial x}\left[C D_{i} \frac{\partial}{\partial x}\left(\frac{C_{i}}{C}\right)\right] \\
& \left.+\frac{\partial}{\partial x}\left[\sum_{i} h_{i} C D_{i} \frac{\partial}{\partial x}\left(\frac{C_{i}}{C}\right)\right]-\sum_{k} Q_{k} R_{k}\right\}
\end{aligned}
$$

where $C_{v}$ is the heat capacity at constant volume, $\lambda$ is the coefficient of thermal conductivity, $\epsilon_{i}$ is the internal energy of component $i, h_{i}$ is the enthalpy of component $i, Q_{k}$ is the enthalpy change for reaction $k$, and $R_{k}$ is the rate of reaction $k$. The Dufour and Soret effects have been neglected, as has been the rate of change of energy due to radiation.

The chemical mechanism used in this study is similar to that used previously [4], and is given in Table 1. Twenty-four components are involved in 76 forward and reverse reactions. The rate coefficients were taken from either of two secondary sources $[17,18]$, and were checked with original references to allow for a choice between conflicting values.

The transport coefficients $D_{i}, \eta$, and $\lambda$ were determined using expressions similar to those used by Lund [1]. The diffusion coefficient $D_{i}$ is a binary diffusion coefficient for diffusion of component $i$ in a bath of the diluent, Ar. The expression we used is as follows:

$$
D_{i}=\frac{D_{i}^{0}}{C} \sqrt{\frac{T}{\mu_{i \mathrm{Ar}}}},
$$

where $D_{i}{ }^{0}$ is a constant and $\mu_{i \mathrm{Ar}}$ is the reduced mass of the component $i$-Ar pair. The value of $D_{i}{ }^{0}$ was determined by performing several test runs on a stoichiometric $\mathrm{CH}_{4}-\mathrm{O}_{2}-\mathrm{N}_{2}$ mixture at a constant pressure of $4.0 \mathrm{kPa}$ and $T=300 \mathrm{~K}$ in the unburned gas. Different values of $D_{i}{ }^{0}$ were used to determine which value resulted in the calculation of the predicted flame speed. The value of $D_{i}{ }^{0}$ so obtained was then kept constant throughout all further calculations. The expressions for $\eta$ and $\lambda$ also contained a parameter:

$$
\eta=C_{\mathrm{p}} \frac{\eta^{0}}{C} \sqrt{T}, \quad \lambda=C_{\mathrm{p}} \frac{\lambda^{0}}{C} \sqrt{T},
$$

where $C_{\mathrm{p}}$ is the total heat capacity at constant pressure of the mixture and $\eta^{0}$ and $\lambda^{0}$ are constants determined in a similar manner to $D_{i}{ }^{0}$. Table 2 gives some representative values of the calculated transport coefficients and comparisons with transport coefficients of known mixtures obtained either from experiments or from calculations using the Chapman-Enskog formulas [16]. The good agreement we find gives us confidence in the values obtained from these approximate expressions. It also gives us some assurance that our calculations are not adversely affected by numerical diffusion.

An article appeared after the completion of these calculations describing simplified models for the transport coefficients [19] which do not involve adjustable parameters such as $D_{i}{ }^{0}, \eta^{0}$, and $\lambda^{0}$. Even though the transport coefficient model used by us is somewhat crude by comparison, we point to the work of Westbrook and Dryer [4] as an example of how well this model works when the parameters are adjusted to give agreement with flame properties at a single flame condition. We shall discuss when appropriate the consequences of inaccuracies in our treatment of the transport coefficients. It should become clear that our conclusions will not be adversely affected. 
TABLE 1

Reaction Mechanism

\begin{tabular}{|c|c|c|c|c|}
\hline & Reaction & $\log A$ & $n$ & $E_{\mathrm{a}}(\mathrm{kcal} / \mathrm{mol})$ \\
\hline 1 & $\mathrm{CH}_{4}+\mathrm{H} \rightarrow \mathrm{CH}_{3}+\mathrm{H}_{2}$ & 14.1 & 0 & 11.8 \\
\hline 2 & $\mathrm{CH}_{4}+\mathrm{OH} \rightarrow \mathrm{CH}_{3}+\mathrm{H}_{2} \mathrm{O}$ & 12.5 & 0 & 3.75 \\
\hline 3 & $\mathrm{CH}_{4}+\mathrm{O} \rightarrow \mathrm{CH}_{3}+\mathrm{OH}$ & 13.2 & 0 & 9.2 \\
\hline 4 & $\mathrm{HCO}+\mathrm{OH} \rightarrow \mathrm{CO}+\mathrm{H}_{2} \mathrm{O}$ & 14.0 & 0 & 0.0 \\
\hline 5 & $\mathrm{OH}+\mathrm{CO} \rightarrow \mathrm{CO}_{2}+\mathrm{H}$ & 7.22 & 1.3 & -0.66 \\
\hline 6 & $\mathrm{H}+\mathrm{O}_{2} \rightarrow \mathrm{OH}+\mathrm{O}$ & 14.3 & 0 & 16.7 \\
\hline 7 & $\mathrm{O}+\mathrm{H}_{2} \rightarrow \mathrm{OH}+\mathrm{H}$ & 10.3 & 1.0 & 8.8 \\
\hline 8 & $\mathrm{O}+\mathrm{H}_{2} \mathrm{O} \rightarrow \mathrm{OH}+\mathrm{OH}$ & 13.8 & 0 & 18.2 \\
\hline 9 & $\mathrm{H}+\mathrm{H}_{2} \mathrm{O} \rightarrow \mathrm{OH}+\mathrm{H}_{2}$ & 14.0 & 0 & 20.3 \\
\hline 10 & $\mathrm{OH}+\mathrm{OH} \rightarrow \mathrm{H}_{2}+\mathrm{O}_{2}$ & 13.4 & 0 & 26.6 \\
\hline 11 & $\mathrm{CO}_{2}+\mathrm{O} \rightarrow \mathrm{CO}+\mathrm{O}_{2}$ & 12.4 & 0 & 43.7 \\
\hline 12 & $\mathrm{H}+\mathrm{HCO} \rightarrow \mathrm{CO}+\mathrm{H}_{2}$ & 14.3 & 0 & 0.0 \\
\hline 13 & $\mathrm{O}+\mathrm{HCO} \rightarrow \mathrm{CO}+\mathrm{OH}$ & 14.0 & 0 & 0.0 \\
\hline 14 & $\mathrm{OH}+\mathrm{H}_{2} \mathrm{CO} \rightarrow \mathrm{HCO}+\mathrm{H}_{2} \mathrm{O}$ & 14.7 & 0 & 6.26 \\
\hline 15 & $\mathrm{H}+\mathrm{H}_{2} \mathrm{CO} \rightarrow \mathrm{H}_{2}+\mathrm{HCO}^{2}$ & 13.1 & 0 & 3.74 \\
\hline 16 & $\mathrm{O}+\mathrm{H}_{2} \mathrm{CO} \rightarrow \mathrm{OH}+\mathrm{HCO}$ & 13.7 & 0 & 4.57 \\
\hline 17 & $\mathrm{CH}_{3}+\mathrm{OH} \rightarrow \mathrm{H}_{2} \mathrm{CO}+\mathrm{H}_{2}$ & 12.6 & 0 & 0.0 \\
\hline 18 & $\mathrm{CH}_{3}+\mathrm{O} \rightarrow \mathrm{H}_{2} \mathrm{CO}+\mathrm{H}$ & 14.1 & 0 & 2.0 \\
\hline 19 & $\mathrm{CH}_{3}+\mathrm{O}_{2} \rightarrow \mathrm{CH}_{3} \mathrm{O}+\mathrm{O}$ & 13.7 & 0 & 28.8 \\
\hline 20 & $\mathrm{CH}_{3}+\mathrm{H}_{2} \mathrm{CO} \rightarrow \stackrel{\mathrm{CH}}{4}+\mathrm{HCO}$ & 10.0 & 0.5 & 6.0 \\
\hline 21 & $\mathrm{CH}_{3}+\mathrm{HCO} \rightarrow \mathrm{CH}_{4}+\mathrm{CO}$ & 11.5 & 0.5 & 0.0 \\
\hline 22 & $\mathrm{O}+\mathrm{HO}_{2} \rightarrow \mathrm{O}_{2}+\mathrm{OH}$ & 13.7 & 0 & 1.0 \\
\hline 23 & $\mathrm{HCO}+\mathrm{HO}_{2} \rightarrow \mathrm{H}_{2} \mathrm{CO}+\mathrm{O}_{2}$ & 14.0 & 0 & 3.0 \\
\hline 24 & $\mathrm{CH}_{3} \mathrm{O}+\mathrm{O}_{2} \rightarrow \mathrm{HO}_{2}+\mathrm{H}_{2} \mathrm{CO}$ & 12.0 & 0 & 6.0 \\
\hline 25 & $\mathrm{CH}_{3}+\mathrm{HO}_{2} \rightarrow \mathrm{CH}_{4}+\mathrm{O}_{2}$ & 12.0 & 0 & 0.4 \\
\hline 26 & $\mathrm{HCO}+\mathrm{O}_{2} \rightarrow \mathrm{CO}+\mathrm{HO}_{2}$ & 12.5 & 0 & 7.0 \\
\hline 27 & $\mathrm{H}+\mathrm{HO}_{2} \rightarrow \mathrm{OH}+\mathrm{OH}$ & 14.4 & 0 & 1.9 \\
\hline 28. & $\mathrm{H}+\mathrm{HO}_{2} \rightarrow \mathrm{H}_{2}+\mathrm{O}_{2}$ & 13.4 & 0 & 0.7 \\
\hline 29 & $\mathrm{OH}+\mathrm{HO}_{2} \rightarrow \mathrm{H}_{2} \mathrm{O}+\mathrm{O}_{2}$ & 13.7 & 0 & 1.0 \\
\hline 30 & $\mathrm{H}_{2} \mathrm{O}_{2}+\mathrm{O}_{2} \rightarrow \mathrm{HO}_{2}+\mathrm{HO}_{2}$ & 13.6 & 0 & 42.3 \\
\hline 31 & $\mathrm{H}_{2} \mathrm{O}_{2}+\mathrm{H} \rightarrow \mathrm{HO}_{2}+\mathrm{H}_{2}$ & 12.2 & 0 & 3.8 \\
\hline 32 & $\mathrm{CH}_{4}+\mathrm{HO}_{2} \rightarrow \mathrm{CH}_{3}+\overline{\mathrm{H}}_{2} \mathrm{O}_{2}$ & 13.3 & 0 & 17.9 \\
\hline 33 & $\mathrm{H}_{2} \mathrm{CO}+\mathrm{HO}_{2} \rightarrow \mathrm{HCO}+\mathrm{H}_{2} \mathrm{O}_{2}$ & 12.0 & 0 & 6.3 \\
\hline 34 & $\mathrm{CO}+\mathrm{HO}_{2} \rightarrow \mathrm{CO}_{2}+\mathrm{OH}$ & 14.0 & 0 & 23.0 \\
\hline 35 & $\mathrm{H}_{2} \mathrm{O}_{2}+\mathrm{OH} \rightarrow \mathrm{H}_{2} \mathrm{O}+\mathrm{HO}_{2}$ & 13.0 & 0 & 1.8 \\
\hline 36 & $\mathrm{CH}_{3}+\mathrm{HO}_{2} \rightarrow \mathrm{CH}_{3} \mathrm{O}+\mathrm{OH}$ & 13.3 & 0 & 0.0 \\
\hline 37 & $\mathrm{C}_{2} \mathrm{H}_{6}+\mathrm{CH}_{3} \rightarrow \mathrm{C}_{2} \mathrm{H}_{5}+\mathrm{CH}_{4}$ & -0.26 & 4 & 8.3 \\
\hline 38 & $\mathrm{C}_{2} \mathrm{H}_{4}+\mathrm{O} \rightarrow \mathrm{CH}_{3}+\mathrm{HCO}$ & 13.5 & 0 & 5.0 \\
\hline 39 & $\mathrm{C}_{2} \mathrm{H}_{6}+\mathrm{H} \rightarrow \mathrm{C}_{2} \mathrm{H}_{5}+\mathrm{H}_{2}$ & 14.1 & 0 & 9.4 \\
\hline 40 & $\mathrm{C}_{2} \mathrm{H}_{5}+\mathrm{O}_{2} \rightarrow \mathrm{C}_{2} \mathrm{H}_{4}+\mathrm{HO}_{2}$ & 12.0 & 0 & 5.0 \\
\hline 41 & $\mathrm{C}_{2} \mathrm{H}_{6}+\mathrm{OH} \rightarrow \mathrm{C}_{2} \mathrm{H}_{5}+\mathrm{H}_{2} \mathrm{O}$ & 13.0 & 0 & 2.4 \\
\hline 42 & $\mathrm{C}_{2} \mathrm{H}_{6}+\mathrm{O} \rightarrow \mathrm{C}_{2} \mathrm{H}_{5}+\mathrm{OH}^{2}$ & 13.4 & 0 & 6.4 \\
\hline 43 & $\mathrm{C}_{2} \mathrm{H}_{5}+\mathrm{C}_{2} \mathrm{H}_{3} \rightarrow \mathrm{C}_{2} \mathrm{H}_{4}+\mathrm{C}_{2} \mathrm{H}_{4}$ & 17.5 & 0 & 35.6 \\
\hline 44 & $\mathrm{C}_{2} \mathrm{H}_{4}+\mathrm{H} \rightarrow \mathrm{C}_{2} \mathrm{H}_{3}+\mathrm{H}_{2}$ & 13.8 & 0 & 6.0 \\
\hline 45 & $\mathrm{C}_{2} \mathrm{H}_{4}+\mathrm{OH} \rightarrow \mathrm{C}_{2} \mathrm{H}_{3}+\mathrm{H}_{2} \mathrm{O}$ & 14.0 & 0 & 3.5 \\
\hline 46 & $\mathrm{C}_{2} \mathrm{H}_{4}+\mathrm{O} \rightarrow \mathrm{H}_{2} \mathrm{CO}+\mathrm{CH}_{2}$ & 13.4 & 0 & 5.0 \\
\hline 47 & $\mathrm{C}_{2} \mathrm{H}_{2}+\mathrm{O}_{2} \rightarrow \mathrm{HCO}+\mathrm{HCO}$ & 14.0 & 0 & 38.0 \\
\hline 48 & $\mathrm{C}_{2} \mathrm{H}_{2}+\mathrm{H} \rightarrow \mathrm{C}_{2} \mathrm{H}+\mathrm{H}_{2}$ & 14.3 & 0 & 19.0 \\
\hline 49 & $\mathrm{C}_{2} \mathrm{H}_{2}+\mathrm{OH} \rightarrow \mathrm{C}_{2} \mathrm{H}+\mathrm{H}_{2} \mathrm{O}$ & 12.8 & 0 & 7.0 \\
\hline 50 & $\mathrm{C}_{2} \mathrm{H}_{2}+\mathrm{O} \rightarrow \mathrm{C}_{2} \mathrm{H}+\mathrm{OH}$ & 15.5 & -0.6 & 17.0 \\
\hline 51 & $\mathrm{C}_{2} \mathrm{H}_{2}+\mathrm{O} \rightarrow \mathrm{CH}_{2}+\mathrm{CO}$ & 13.8 & 0 & 4.0 \\
\hline 52 & $\mathrm{C}_{2} \mathrm{H}+\mathrm{O}_{2} \rightarrow \mathrm{HCO}+\mathrm{CO}$ & 13.0 & 0 & 7.0 \\
\hline
\end{tabular}


TABLE 1 (Continued)

\begin{tabular}{|c|c|c|c|c|}
\hline & Reaction & $\log A$ & $\eta$ & $E_{\mathrm{a}}(\mathrm{kcal} / \mathrm{mol})$ \\
\hline 53 & $\mathrm{C}_{2} \mathrm{H}+\mathrm{O} \rightarrow \mathrm{CO}+\mathrm{CH}$ & 13.7 & 0 & 0.0 \\
\hline 54 & $\mathrm{CH}_{2}+\mathrm{O}_{2} \rightarrow \mathrm{HCO}+\mathrm{OH}$ & 14.0 & 0 & 3.7 \\
\hline 55 & $\mathrm{CH}_{2}+\mathrm{O} \rightarrow \mathrm{CH}+\mathrm{OH}$ & 11.3 & 0.68 & 25.0 \\
\hline 56 & $\mathrm{CH}_{2}+\mathrm{H} \rightarrow \mathrm{CH}+\mathrm{H}_{2}$ & 11.4 & 0.67 & 25.6 \\
\hline 57 & $\mathrm{CH}+\mathrm{O}_{2} \rightarrow \mathrm{CO}+\mathrm{OH}$ & 11.1 & 0.67 & 25.6 \\
\hline 58 & $\mathrm{CH}_{2}+\mathrm{OH} \rightarrow \mathrm{CH}+\mathrm{H}_{2} \mathrm{O}$ & 11.4 & 0.67 & 25.6 \\
\hline 59 & $\mathrm{CH}+\mathrm{O}_{2} \rightarrow \mathrm{HCO}+\mathrm{O}$ & 13.0 & 0 & 0 \\
\hline 60 & $\mathrm{CH}_{4}+\mathrm{M} \rightarrow \mathrm{CH}_{3}+\mathrm{H}+\mathrm{M}$ & 17.1 & 0 & 87.8 \\
\hline 61 & $\mathrm{HCO}+\mathrm{M} \rightarrow \mathrm{H}+\mathrm{CO}+\mathrm{M}$ & 14.4 & 0 & 18.9 \\
\hline 62 & $\mathrm{H}+\mathrm{O}+\mathrm{M} \rightarrow \mathrm{OH}+\mathrm{M}$ & 15.9 & 0 & 0.0 \\
\hline 63 & $\mathrm{O}_{2}+\mathrm{M} \rightarrow \mathrm{O}+\mathrm{O}+\mathrm{M}$ & 15.7 & 0 & 115.0 \\
\hline 64 & $\mathrm{H}_{2}+\mathrm{M} \rightarrow \mathrm{H}+\mathrm{H}+\mathrm{M}$ & 14.3 & 0 & 96.0 \\
\hline 65 & $\mathrm{H}_{2} \mathrm{O}+\mathrm{M} \rightarrow \mathrm{H}+\mathrm{OH}+\mathrm{M}$ & 16.3 & 0 & 104.5 \\
\hline 66 & $\mathrm{H}+\mathrm{O}_{2}+\mathrm{M} \rightarrow \mathrm{HO}_{2}+\mathrm{M}$ & 15.2 & 0.0 & -0.1 \\
\hline 67 & $\mathrm{CO}+\mathrm{O}+\mathrm{M} \rightarrow \mathrm{CO}_{2}+\mathrm{M}$ & 15.8 & 0 & 4.1 \\
\hline 68 & $\mathrm{H}_{2} \mathrm{CO}+\mathrm{M} \rightarrow \mathrm{H}+\mathrm{HCO}+\mathrm{M}$ & 16.7 & 0 & 72.0 \\
\hline 69 & $\mathrm{CH}_{3} \mathrm{O}+\mathrm{M} \rightarrow \mathrm{H}_{2} \mathrm{CO}+\mathrm{H}+\mathrm{M}$ & 13.7 & 0 & 20.9 \\
\hline 70 & $\mathrm{O}+\mathrm{OH}+\mathrm{M} \rightarrow \mathrm{HO}_{2}+\mathrm{M}$ & 17.0 & 0 & 0.0 \\
\hline 71 & $\mathrm{H}_{2} \mathrm{O}_{2}+\mathrm{M} \rightarrow \mathrm{OH}+\mathrm{OH}+\mathrm{M}$ & 17.1 & 0 & 45.5 \\
\hline 72 & $\mathrm{C}_{2} \mathrm{H}_{4}+\mathrm{M} \rightarrow \mathrm{C}_{2} \mathrm{H}_{3}+\mathrm{H}+\mathrm{M}$ & 17.6 & 0 & 98.2 \\
\hline 73 & $\mathrm{C}_{2} \mathrm{H}_{3}^{*}+\mathrm{M} \rightarrow \mathrm{C}_{2} \mathrm{H}_{2}+\mathrm{H}+\mathrm{M}$ & 14.9 & 0 & 31.6 \\
\hline 74 & $\mathrm{C}_{2} \mathrm{H}_{2}+\mathrm{M} \rightarrow \mathrm{C}_{2} \mathrm{H}+\mathrm{H}+\mathrm{M}$ & 14.0 & 0 & 114.0 \\
\hline 75 & $\mathrm{C}_{2} \mathrm{H}_{5} \rightarrow \mathrm{C}_{2} \mathrm{H}_{4}+\mathrm{H}$ & 13.6 & 0 & 38.0 \\
\hline 76 & $\mathrm{C}_{2} \mathrm{H}_{6} \rightarrow \mathrm{CH}_{3}+\mathrm{CH}_{3}$ & 16.3 & 0 & 87.2 \\
\hline
\end{tabular}

The thermodynamic properties of the components used in this calculation were calculated from heat capacities of the individual components. These heat capacities were used in the form of fifth-order polynomial fits to the temperature, and were taken from the compilation of Westbrook and Chase [17].

The idealized physical situation we simulate in these calculations consists of a 4-cm-long container filled with a 4.0-kPa mixture of $\mathrm{CH}_{4}, \mathrm{O}_{2}$, and $\mathrm{Ar}$ at an equivalence ratio of $\phi=0.85$. The mixture is ignited near the left boundary of the container, and the flame propagates toward the right boundary. Three different boundary conditions are used at the right boundary: (1) isothermal at $373 \mathrm{~K}$ and inert; (2) adiabatic and $100 \%$ efficient at destroying radicals; (3) isothermal at $373 \mathrm{~K}$ and $100 \%$ efficient at destroying radicals. These three possibilities will be henceforth referred to as cases I, II, and III. The mathematical expressions at the boundaries and their corresponding physical mean- ings are summarized in Table 3 . This configuration can be modeled in one spatial dimension if it is assumed that there are no gradients of the system variables along coordinates orthogonal to the single spatial coordinate employed in the calculation. This condition would be satisfied in a rectangular box if the flame propagated across the box as a plane wave over at least part of the flame front.

The mixture is ignited with an initial temperature and $\mathrm{H}$ atom distribution which is described by the function $\exp \left(-32.5 x^{2}\right)$. The induction period in our calculations is reduced by the addition of $\mathrm{H}$ atoms much more than by either an initially high temperature or a time-dependent energy source.

A crevice is introduced by adding a heat loss term in the one-dimensional energy equation which accounts in an approximate way for the effect of the cooled crevice wall on the gas in the crevice. The form of this heat loss term can be demonstrated by referring to Fig. 1. The crevice 
TABLE 2

Comparison of Transport Coefficients

\begin{tabular}{lrccc}
\hline \multicolumn{5}{l}{ Coefficient of Diffusion $\left(\mathrm{cm}^{2} \mathrm{~s}^{-1}\right)$} \\
\hline Mixture & \multicolumn{1}{l}{$T(\mathrm{~K})$} & $\mathrm{p}$ & $D_{i j}(C-E)$ & $D_{i j}$ (calc) \\
\hline $\mathrm{Ar}-\mathrm{H}_{2}$ & 746 & $1 \mathrm{~atm}$ & 3.65 & 3.6 \\
$\mathrm{Ar}-\mathrm{H}_{2}$ & 1492 & $1 \mathrm{~atm}$ & 11.5 & 10.3 \\
$\mathrm{~N}_{2}-\mathrm{H}_{2}$ & 739 & $1 \mathrm{~atm}$ & 3.45 & 3.62 \\
$\mathrm{~N}_{2}-\mathrm{H}_{2}$ & 1478 & $1 \mathrm{~atm}$ & 11.0 & 10.2 \\
$\mathrm{~N}_{2}-\mathrm{O}_{2}$ & 988 & $1 \mathrm{~atm}$ & 1.57 & 1.98 \\
$\mathrm{~N}_{2}-\mathrm{O}_{2}$ & 1976 & $1 \mathrm{~atm}$ & 4.98 & 5.6
\end{tabular}

Coefficient of thermal conductivity (cal cm-1 s $\mathrm{s}^{-1} \mathrm{deg}^{-1}$ )

\begin{tabular}{|c|c|c|c|}
\hline Mixture & $T(\mathrm{~K})$ & $\lambda(\operatorname{exptl}.) \times 10^{7}$ & $\lambda(\mathrm{calc}) \times 10^{7}$ \\
\hline $15.9 \% \mathrm{H}_{2}-\mathrm{N}_{2}$ & 273 & 800 & 673 \\
\hline $\mathrm{H}_{2}-\mathrm{Ar}$ & 273 & 2010 & 2305 \\
\hline $9.0 \% \mathrm{H}_{2}-\mathrm{Ar}$ & 273 & 550 & 512 \\
\hline $28.85 \% \mathrm{H}_{2}$ in $\mathrm{CO}_{2}$ & 893 & 2930 & 1980 \\
\hline $10 \% \mathrm{H}_{2} \mathrm{O}$ in $\mathrm{N}_{2}$ & 603 & 1130 & 1087 \\
\hline \multicolumn{4}{|c|}{ Coefficient of viscosity $\left(\mathrm{g} \mathrm{cm}^{-1} \mathrm{~s}^{-1}\right)$} \\
\hline Mixture & $T(\mathrm{~K})$ & $\eta(\operatorname{exptl}) \times 10^{7}$ & $\eta$ (calc) $\times 10^{7}$ \\
\hline \multicolumn{4}{|l|}{$10.8 \% \mathrm{CO}_{2}, 2 \% \mathrm{O}_{2}$} \\
\hline $2.2 \% \mathrm{H}_{2}, 85 \% \mathrm{~N}_{2}$ & 973 & 4117 & $\begin{array}{l}5191 \\
2247\end{array}$ \\
\hline $\mathrm{H}_{2}-\mathrm{N}_{2}$ & 273 & 1670 & 2247 \\
\hline $\mathrm{N}_{2}-\mathrm{Ar}$ & 273 & 2010 & 1760 \\
\hline
\end{tabular}

is constructed by adding one mesh point in the $+y$ direction and one point in the $-y$ direction adjacent to mesh points on the $x$ axis. These extra points begin at the right boundary and extend in the $-x$ direction for a distance equal to the desired depth of the crevice. We then require that the temperature at these points off the $x$ axis be equal to the wall temperature, and we introduce in the temperature equation the third-order accurate finite difference approximation to describe heat transfer in the $y$ direction:

$\left(\frac{\partial}{\partial y}\right) \lambda \frac{\partial T}{\partial y} \approx 2 \lambda \frac{\left(T_{\text {wall }}-T(x)\right)}{\Delta y^{2}}$.

Here $\lambda$ is the coefficient of thermal conductivity of the gas for $T=T(x)$ and for simplicity is assumed to be independent of the $y$ coordinate. $T_{\mathrm{wall}}$ is the wall temperature of the crevice and of the wall in which the crevice is located (373K), and $T(x)$ is the temperature of the gas along the $x$ axis which is to be determined by the simultaneous solution of the conservation equations (1)-(4). Other $y$ derivative terms in Eq. (4) were

TABLE 3

Boundary Conditions

\begin{tabular}{|c|c|c|c|}
\hline & & Right boundary & Left boundary \\
\hline \multirow[t]{3}{*}{ Case I: } & $\begin{array}{l}\text { cooled inert } \\
\text { surface }\end{array}$ & $\frac{\partial C_{i}}{\partial x}=0$ & $\frac{\partial C_{i}}{\partial x}=0$ \\
\hline & & $\nu=0$ & $\nu=0$ \\
\hline & & $T=373 \mathrm{~K}$ & $\frac{\partial T}{\partial x}=0$ \\
\hline \multirow[t]{3}{*}{ Case II: } & $\begin{array}{l}\text { adiabatic } \\
\text { cataly tically } \\
\text { active surface }\end{array}$ & $\begin{aligned} \mathrm{C}_{\mathrm{H}}=\mathrm{C}_{\mathrm{O}} & =\mathrm{C}_{\mathrm{OH}} \\
& =6.67 \times 10^{-13 \mathrm{~mol} \mathrm{~cm}-3}\end{aligned}$ & $\frac{\partial C_{i}}{\partial x}=0$ \\
\hline & & $\nu=0$ & $\nu=0$ \\
\hline & & $\frac{\partial T}{\partial x}=0$ & $\frac{\partial T}{\partial x}=0$ \\
\hline \multirow[t]{3}{*}{ Case III: } & $\begin{array}{l}\text { cooled catalytically } \\
\text { active surface }\end{array}$ & $\begin{aligned} C_{H} & =C_{0}=C_{O H} \\
& =6.67 \times 10^{-13} \mathrm{~mol} \mathrm{~cm}^{-3}\end{aligned}$ & $\frac{\partial C_{i}}{\partial x}=0$ \\
\hline & & $\nu=0$ & $\nu=0$ \\
\hline & & $T=373 \mathrm{~K}$ & $\frac{\partial 1}{\partial x}=0$ \\
\hline
\end{tabular}




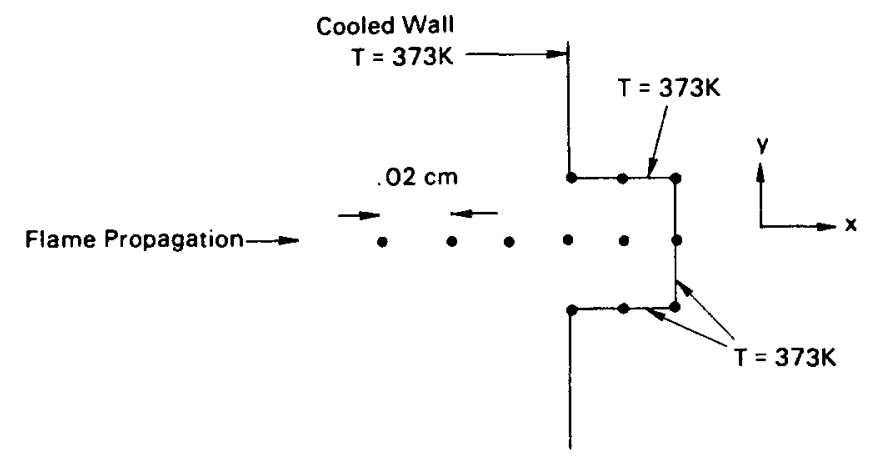

Fig. 1. Crevice diagram, including the physical location of the cooled wall (solid lines) and the mesh points used in the calculation (dots).

neglected because their contribution to the righthand side is negligible for the conditions we are considering.

The value used for $\Delta y$ is $0.02 \mathrm{~cm}$, the same spacing as for $\Delta x$ in that region of the mesh. This results in a crevice $0.04 \mathrm{~cm}$ wide which is bounded by a layer of inert gas (rather than a solid boundary) held at $T=T_{w}$ all through which no material passes. Since the coefficient of thermal conductivity is greater for heat transfer to a surface than to a gas, this expression deliberately underestimates the effect of the low crevice wall temperature on the temperature of the combustible mixture inside the crevice. This is compensated for to a limited extent by evaluating $\lambda$ at $T(x)$ and assuming that it is independent of $y$.

The 0.02-cm-mesh spacing in the $y$ direction inside the crevice should adequately describe the gradients which will be present there. The reason for this is that since the flame cannot penetrate the crevice, the temperature and concentration gradients in the $y$ direction can be no steeper than the gradients in the $x$ direction near a flat cooled surface. A mesh spacing of $0.02 \mathrm{~cm}$ describes very well the gradients near the end wall in the absence of a crevice, so the same spacing should be adequate in the $y$ direction inside the crevice. We know that the flame does not penetrate the crevice because Friedman and Johnston [20] have shown that a flame will not penetrate between two plates unless the single-wall quench distance is less than about $40 \%$ of the spacing. This means that the quench layer in our calculations would have to be less than $0.016 \mathrm{~cm}$ in order for the flame to pene- trate the crevice. As will be seen, however, the quench layer thickness is about $0.06 \mathrm{~cm}$. Therefore the thermal boundary layer at the wall will completely cover the opening of the crevice.

This model assumes that the crevice extends indefinitely in the $z$ direction. Although we have not done so here, we could easily define the crevice to be a hole with a square cross section 0.04 $\mathrm{cm}$ high and $0.04 \mathrm{~cm}$ wide. The appropriate expression to be included in Eq. (4) would then be two times the right-hand side of (5).

\section{METHOD OF SOLUTION}

The equations are solved with the partial differential equations solver PDEPACK [21]. This package uses the method of lines to solve problems described by time-dependent partial differential equations with one spatial dimension. The spatial derivatives are discretized with centered differences which give third-order accuracy for second derivatives and second-order accuracy for first derivatives. The resulting set of ordinary differential equations is then solved with a modified version of the Gear integrator. We employ an analytic Jacobian matrix and restrict the maximum order of time integration to two.

PDEPACK requires that the chosen mesh be constant in time. For these low-pressure calculations we have chosen a mesh spacing of $0.033 \mathrm{~cm}$ for all of the mesh except for $x=3.90 \mathrm{~cm}$ to $x=$ $4.00 \mathrm{~cm}$ where the mesh spacing is $0.02 \mathrm{~cm}$. This gives us a little more resolution near the right 
boundary, where the quenching is taking place, at the expense of a small loss of accuracy in the immediate region of the mesh change. Test calculations with a uniform mesh spacing of $0.02 \mathrm{~cm}$ exhibited no significant differences, supporting our choice as a good trade-off between accuracy and computation time.

Higher-pressure calculations will require finer spatial resolution in the high-gradient region (the flame front). As a uniformly fine mesh is computationally very expensive, a preferable strategy is to allow the mesh to change in time, with a region of high resolution progressing with the front-the so-called dynamic rezoning. This device is employed with considerable advantage in the HCT [1] code. We are presently attempting to implement a dynamic rezoning algorithm in PDEPACK in the hope of combining the efficiency of HCT with the flexibility and ease of use of PDEPACK.

The second-order centered difference approximation to $\partial / \partial x$ is known to result in spurious oscillations in some solution components for problems which involve fluid flow [22]. Oscillations in the velocity profiles are apparent early in the calculations, but by the time the flame reaches the quenching surface the oscillations have been damped considerably because of the viscous dissipation. Therefore we were able to carry out the calculations without using an artificial viscosity. Further computations showed that increasing the viscosity parameter $\eta^{0}$ by up to a factor of 10 would damp out these oscillations without appreciably changing the results. We avoided various firstorder upwind differencing schemes because tests showed them to be insufficiently accurate.

A more rigorous treatment of the mathematical model defined by Eq. (1)-(4) would require use of an appropriate higher-order difference approximation for $\partial / \partial x$ (and possibly for the second-derivative terms as well) to improve the stability of the solution. Substantial internal modifications to PDEPACK would be necessary to carry this out, however.

The calculations performed here typically require about $600 \mathrm{~min}$ of CPU time on the GMR IBM 3033 computer system for a complete burn across $4.00 \mathrm{~cm}$. We have implemented a restart capability in PDEPACK to allow us to carry out these computations in segments spread out over several days. For each mixture a complete calculation beginning with ignition was performed only for cases I and II. The calculations for case III were restarts of the case I calculation with the flame at $x=3.50 \mathrm{~cm}$ with different boundary conditions. Such abrupt changes in the boundary conditions are allowed with PDEPACK, and are also physically reasonable because with the flame at $x=3.50 \mathrm{~cm}$ the concentrations of $\mathrm{H}, \mathrm{O}$, and $\mathrm{OH}$ were effectively zero at the right boundary.

\section{CATALYTIC AND NONCATALYTIC RECOMBINATION AT THE SURFACE}

Typical mole fraction profiles of many of the important flame components and the temperature under conditions where the flame is unaffected by the right boundary are shown in Figs. 2 and 3. At this time the pressure has risen from $4.0 \mathrm{kPa}$ to approximately $9.5 \mathrm{kPa}$.

When this calculation is continued with $T=$ $373 \mathrm{~K}$ at the right boundary, the flame reference position (defined as the point where $T=1500 \mathrm{~K}$ ) approaches the boundary no closer than $0.07 \mathrm{~cm}$ The time when the flame stops propagating toward the right boundary will be referred to as $t_{\mathrm{q}}$, the quenching time, and the distance from the flame front to the right boundary at $t_{\mathrm{q}}$ will be referred to as $X_{\mathbf{q}}$, the quench distance. This is a purely operational definition since the criterion for the flame position is, within limits, somewhat arbitrary. Figures 4 and 5 show profiles of the same components shown in Figs. 2 and 3, but at $t_{\mathrm{q}}$ for case $\mathrm{I}$. The pressure at $t_{\mathrm{q}}$ is about $11 \mathrm{kPa}$. Qualitatively the profiles are very similar to those described previously at higher pressure [10]. A layer of unburned fuel remains near the right boundary; the intermediates $\mathrm{CO}$ and $\mathrm{H}_{2}$ peak near the boundary. Other hydrocarbon mole fractions are considerably lower than the methane mole fraction.

The value for $X_{q}$ obtained for this flame seems to be too small for such a low pressure. No experimental results are available for the quench distance of the flame we are modeling here, however. We shall discuss later the consequences of possible 


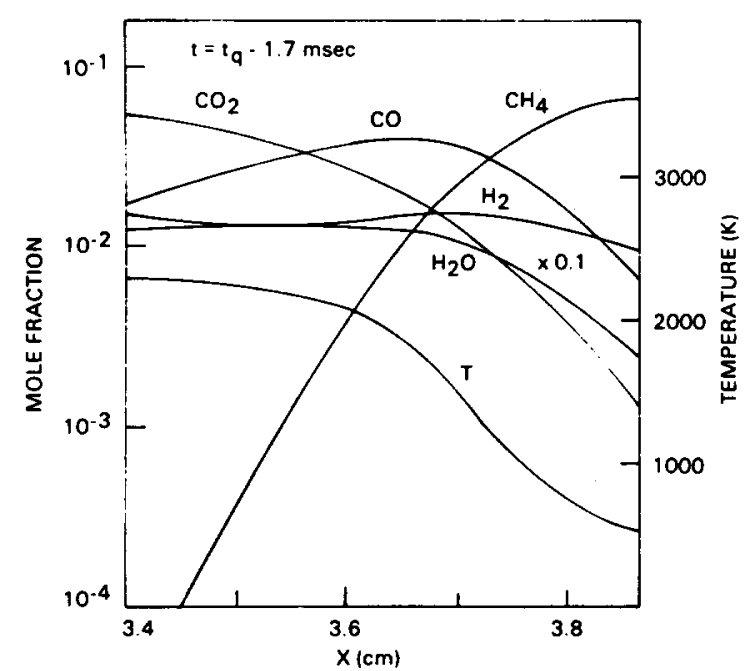

Fig. 2. Mole fraction profiles of the major stable components of the mixture and the temperature profile at a time of $1.7 \mathrm{~ms}$ before the quenching time $t_{\mathbf{q}}$.

errors which could lead to an $X_{q}$ which is too small.

For case II, where the radicals $\mathrm{H}, \mathrm{O}$, and $\mathrm{OH}$ are destroyed at the right boundary but $\partial T / \partial x=$ 0 is the only temperature requirement, the flame

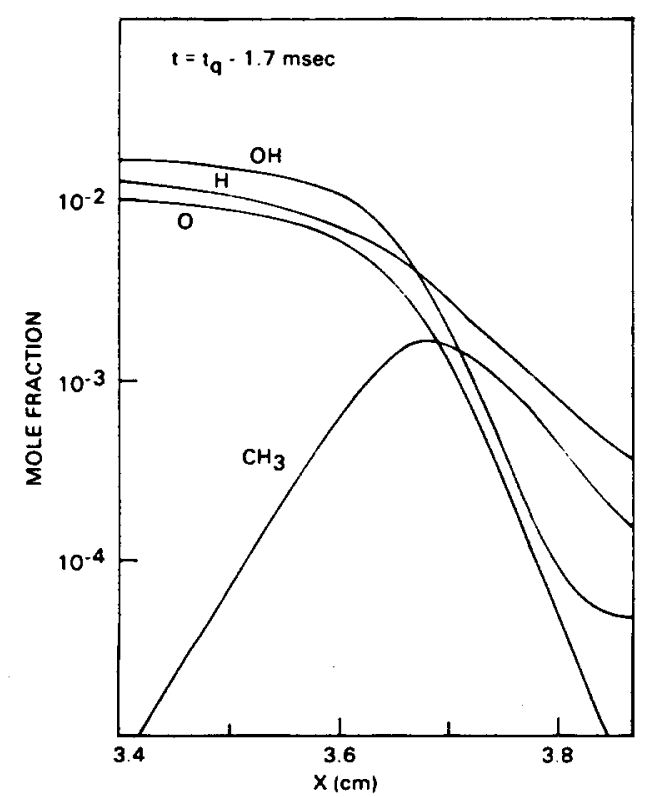

Fig. 3. Mole fraction profiles of the major radical components at $t=t_{\mathbf{q}}-1.7 \mathrm{~ms}$.

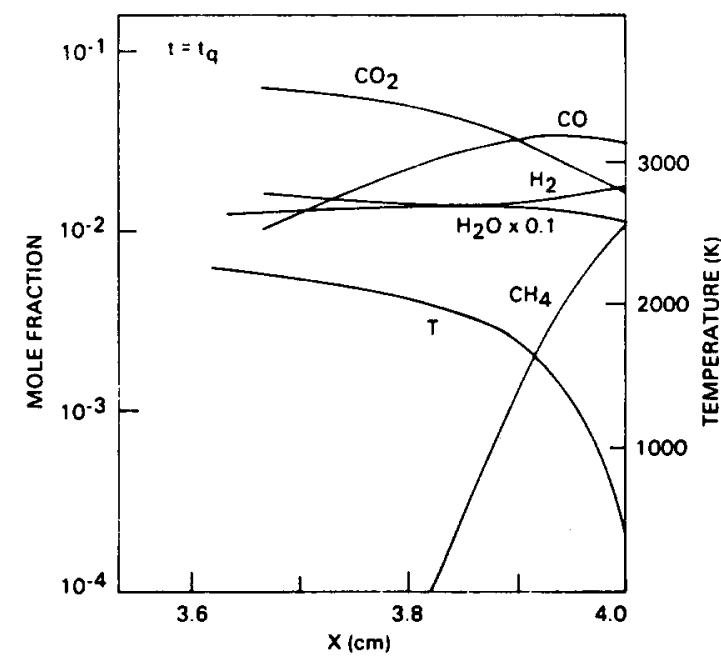

Fig. 4. Mole fraction profiles of the major stable components and the temperature at $t=t_{\mathrm{a}}$ for case $\mathrm{I}(T$ is fixed at $373 \mathrm{~K}$ at the right boundary). Pressure $=11 \mathrm{kPa}$.

does not stop short of the right boundary. Instead, the flame burns all the way to the right boundary in the same amount of time as when the concentrations of $\mathrm{H}, \mathrm{O}$, and $\mathrm{OH}$ are not fixed. Radical destruction alone therefore has no perceptible ef-

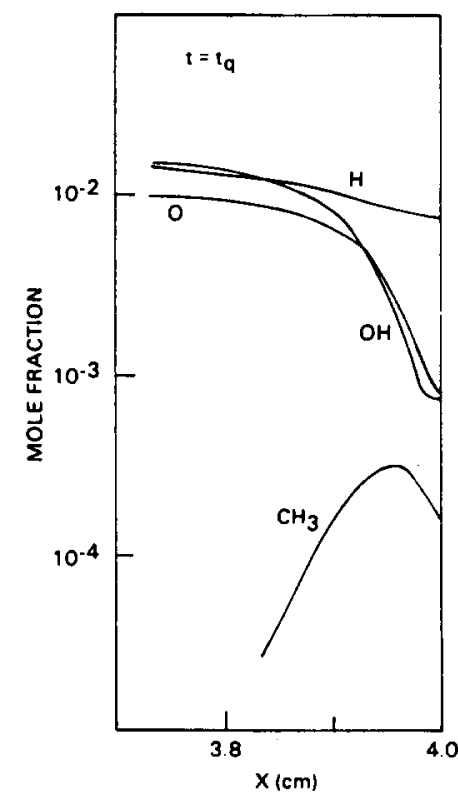

Fig. 5. Mole fraction profiles of the major radical components at $t=t_{\mathrm{Q}}$ for case $\mathrm{I}$. Pressure $=11 \mathrm{kPa}$. 
fect on the burning. This conclusion remains unchanged when all the flame radical concentrations are fixed at $6.67 \times 10^{-13} \mathrm{~mol} \mathrm{~cm}^{-3}$.

The mole fraction profiles for case III at the time of closest approach of the flame to the right boundary were also obtained. The quenching time $t_{\mathrm{q}}$ for case III is identical to $t_{\mathrm{q}}$ for case I within the time step resolution. There are significant differences in the $\mathrm{CH}_{4}, \mathrm{H}, \mathrm{O}$, and $\mathrm{OH}$ mole fractions for the two cases. Although the radical mole fractions decrease near the boundary for case $I$, they decrease even more for case III. $\mathrm{H}, \mathrm{O}$, and $\mathrm{OH}$ are less for case III than for case I between 3.80 and $4.0 \mathrm{~cm}$. The mole fraction of $\mathrm{CH}_{4}$ is everywhere greater for case III than for case I. The major hydrocarbon remaining is $\mathrm{CH}_{4}$ in both cases, as was found previously at higher pressure $[9,10]$. All other hydrocarbon mole fractions are more than a factor of 10 less than $\mathrm{CH}_{4}$.

An important measure of the relative effects of case I verses case III is the difference, if any, in the rate of disappearance of $\mathrm{CH}_{4}$ after $t_{\mathrm{q}}$. The mole fraction of $\mathrm{CH}_{4}$ for both cases is shown in Fig. 6 for $t \geqslant t_{\mathbf{q}}$. In case $\mathrm{I}$, the $\mathrm{CH}_{4}$ is completely consumed by time $t_{\mathrm{a}}+0.7 \mathrm{~ms}$, whereas in case III the $\mathrm{CH}_{4}$ is not completely consumed until $t=t_{\mathrm{q}}+1.6 \mathrm{~ms}$. The computation shows that case III boundary conditions retard the disappearance of $\mathrm{CH}_{4}$ compared to case $\mathrm{I}$, but in either case the $\mathrm{CH}_{4}$ is reduced to a very low level in less than 1 ms.
To determine how this methane disappearance time changes with pressure we have performed a calculation at a terminal pressure of $25 \mathrm{kPa}$. For this pressure $X_{\mathrm{a}}$ is about $0.04 \mathrm{~cm}$. Although the methane disappears more slowly for case III than for case I, the disappearance times are less than for the equivalent calculation at lower pressure. The effect of radical destruction at the surface on the mole fractions of $\mathrm{H}, \mathrm{O}$, and $\mathrm{OH}$ is also less pronounced at this higher pressure.

We now discuss the quench distance and the consequences for our results of calculating an $X_{\mathrm{q}}$ which may be too small. By extrapolating the calculations of Westbrook et al. [10] to the terminal pressure in our calculations, we find that $X_{\mathbf{q}}$ at $25 \mathrm{kPa}$ for a stoichiometric $\mathrm{CH}_{4}-\mathrm{O}_{2}-\mathrm{N}_{2}$ mixture with a $300 \mathrm{~K}$ wall temperature should be about $0.1 \mathrm{~cm}$. A number of our conditions are different from this reference calculation, so a direct comparison is difficult. Also, it is clear that the flame properties of methane change at pressures lower than $1 \mathrm{~atm}$ [23], so an extrapolation to low pressure of high-pressure calculations is particularly dangerous. In order to assess the sensitivity of our comparison between case I and case III to changes in the computed quench distances, we increased the constant $\lambda^{0}$ by a factor of three, and as a result the quench distance increased from 0.04 to $0.07 \mathrm{~cm}$. The quenching time occurred earlier and the $\mathrm{CH}_{4}$ remaining at $t_{\mathrm{a}}$ persisted longer after $t_{\mathbf{q}}$, but the total burning

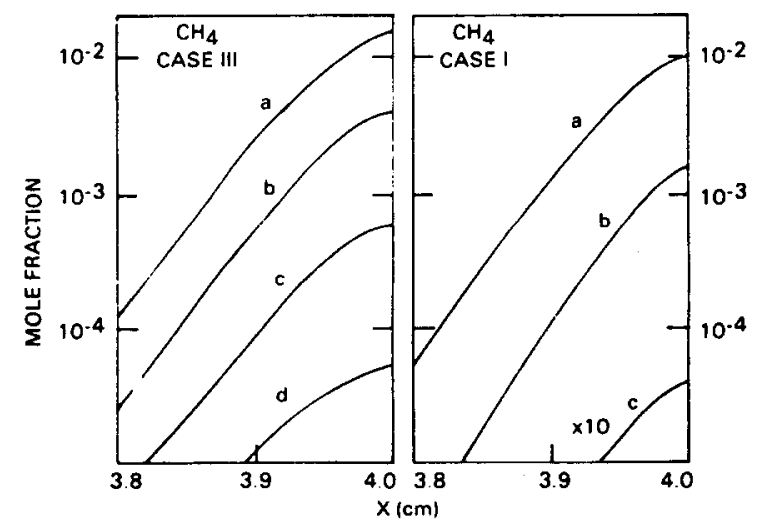

Fig. 6. Methane mole fraction profiles for cases I and III at $t=$ (a) $t_{\mathrm{q}} ;$ (b) $t_{\mathrm{Q}}+0.2 \mathrm{~ms}$; (c) $t_{\mathrm{q}}+0.4 \mathrm{~ms}$; (d) $t_{\mathrm{q}}+1.0 \mathrm{~ms}$. Pressure $=11 \mathrm{kPa}$. 
time was nearly independent of $\lambda^{0}$. The comparison between cases I and III remained unchanged. This result gives us confidence that our comparison of cases I and III is valid even if our quench distances are not exactly correct. We might also add that, for a given pressure, the closer the flame approaches the surface, the more important recombination at the surface should be. If our quenching distance is too small, then we have exaggerated an effect which turned out to be small anyway.

It is interesting to examine the fate of another pollutant, carbon monoxide, after time $t_{\mathbf{q}}$. This molecule disappears much more slowly than methane. Although it is also diffusing rapidly away from the surface, it is being constantly produced by the oxidation of $\mathrm{CH}_{4}$, suggesting that laminar end-wall flame quenching might be a significant source of $\mathrm{CO}$ emissions from engines.

\section{COMPARISON WITH OTHER EXPERIMENTAL AND NUMERICAL RESULTS}

Our results are in general agreement with our previous experimental results [8] and the experiments of other workers [7,9]. Although the physical arrangement of our previous experiments differs from that of the mathematical model, there are important qualitative similarities in the results. Foremost among these are the slow disappearance of $\mathrm{CH}_{4}$ near the cooled surface compared to an undisturbed flame and the eventual complete consumption of $\mathrm{CH}_{4}$. The methane disappearance rates for convection, expansion, reaction, and diffusion which are available from the calculations show that diffusion is the dominant means for removing $\mathrm{CH}_{4}$ from the vicinity of the cooled surface, a conclusion which is not directly obtainable from the experimental data. Rapid oxidation of the methane takes place when it diffuses into the radical-rich high-temperature region.

Radical concentrations also exhibit similar trends in the experiments [8] and the calculations. In both cases the radical mole fractions are low near the surface. The recombination reaction 66 and the reverse of the important chain-propagating reaction 6 are two of the fastest reactions in that region. In the undisturbed flame location at the same temperature, the chemistry is quite different. Reactions 1 and 2, and the reverse of 76 are the fastest reactions there. The rates of reaction 66 and the reverse of reaction 6 are much lower than near the surface. The positive rate of change in the concentrations of $\mathrm{H}, \mathrm{O}$, and $\mathrm{OH}$ near the boundary is due to the dominance of diffusion of these radicals toward the boundary over the net reduction in their concentrations due to chemical reaction. This rate of change is much smaller, however, than at a comparable distance downstream of a freeburning flame.

Westbrook et al. [10] discussed in some detail the drastic change in the chemistry of a methane and methanol flame near a cooled surface at higher pressure. Their paper raised the hypothesis that laminar end-wall quenching may not be an important source of hydrocarbon emissions in engines. Since fuel oxidation in a laminar flat-wall quench layer depends on diffusion of the fuel, our results and those of Westbrook et al. [10] need to be verified for a fuel having the diffusion properties of an actual engine fuel. We did this in an approximate way by stopping at time $t_{\mathbf{q}}$ the calculation with a terminal pressure of $25 \mathrm{kPa}$, changing the mass of methane from 16 to 118 , and then continuing the calculation leaving the chemistry unaltered. This caused a moderate $(\sim 20 \%)$ increase in the amount of time necessary to consume all the fuel. This moderate increase offers evidence that the hypothesis of Westbrook et al. [10] should apply to heavier fuels having reaction rates with flame radicals not appreciably smaller than the rates for $\mathrm{CH}_{4}$ and $\mathrm{CH}_{3} \mathrm{OH}$. However, the validity of this hypothesis is contingent on the oxidation rate of intermediate hydrocarbons formed in the oxidation of gasoline because many more steps are required to oxidize completely a typical hydrocarbon component of gasoline than to oxidize completely methane or methanol.

This work and the work of others [10-15] point very strongly to other causes of hydrocarbon emissions than laminar end-wall or side-wall quenching by cooled inert or radical destroying surfaces. Crevices may be a likely source of these emissions because of the rapid rate of heat transfer to the cooled surface which would occur in a crevice and because of possible restrictions on diffu- 


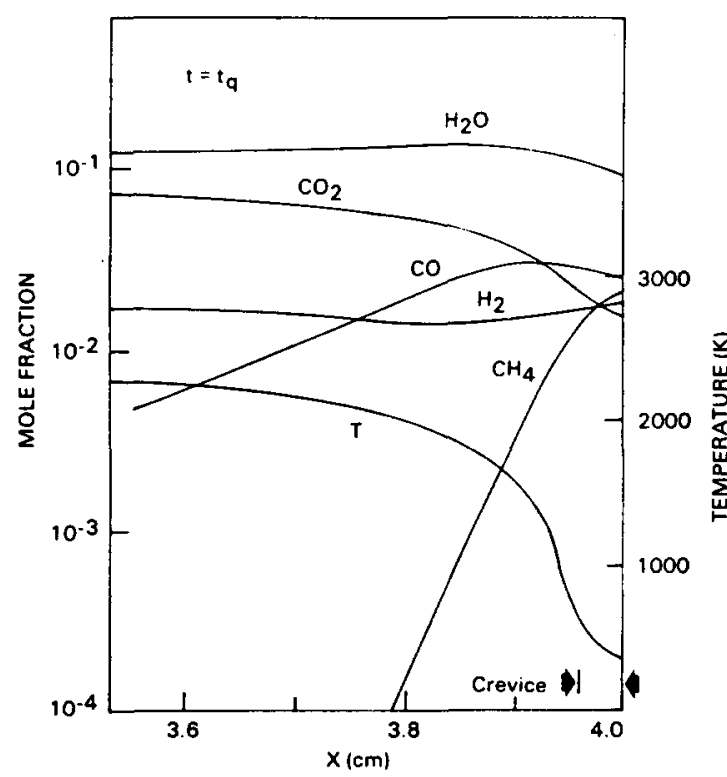

Fig. 7. Mole fraction profiles of the major stable components and the temperature at $t=t_{\mathrm{q}}$ with a crevice $0.04 \mathrm{~cm}$ deep and $0.04 \mathrm{~cm}$ in diameter at the right boundary. Pressure $=11 \mathrm{kPa}$.

sion rates out of the crevice. Computational studies of the effect of crevices on flame quenching for these low-pressure methane-oxygen-argon flames will now be discussed.

\section{CREVICE CALCULATIONS}

The mole fraction profiles of some of the important chemical components and the temperature profile are shown in Figs. 7 and 8 at $t=t_{\mathrm{q}}$ for a flame propagating toward a wall with a $0.04-\mathrm{cm}$ deep and $0.04-\mathrm{cm}$-wide crevice. The distance of closest approach of the flame $(T=1500 \mathrm{~K})$ to the surface is about $0.06 \mathrm{~cm}$, or $0.02 \mathrm{~cm}$ away from the mouth of the crevice. The pressure at $t_{\mathrm{q}}$ is about $11 \mathrm{kPa}$. The most striking effect of the crevice is shown in Fig. 9. The methane persists in the crevice at a significant mole fraction level even $2 \mathrm{~ms}$ after $t_{\mathrm{a}}$ and disappears at one-eighth the rate for the flat wall case.

If the length of the crevice is extended to 0.1 $\mathrm{cm}$, the time scale for removal of the $\mathrm{CH}_{4}$ is correspondingly increased. After $3 \mathrm{~ms}$ the mole

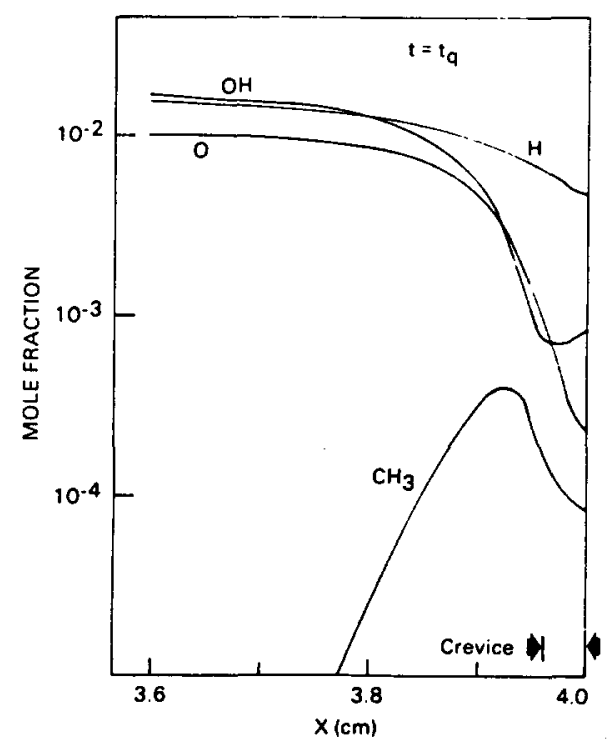

Fig. 8. Mole fraction profiles of the major radical compo nents at $t=t_{\mathrm{q}}$ for a $0.04 \times 0.04 \mathrm{~cm}^{2}$ crevice. Pressure = $11 \mathrm{kPa}$.

fraction of $\mathrm{CH}_{4}$ decreased near the closed enc of the crevice by only a factor of five from it: highest value.

Examination of the rate of disappearance of methane in this region shows that methane re

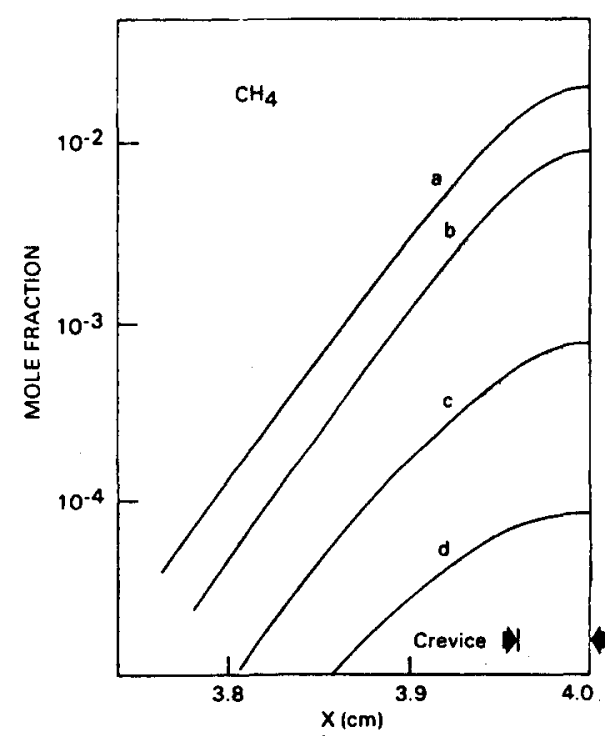

Fig. 9. Methane mole fraction for a $0.04 \times 0.04 \mathrm{~cm}^{2}$ crevice at $t=$ (a) $t_{\mathrm{q}}$; (b) $t_{\mathrm{q}}+0.3 \mathrm{~ms}$; (c) $t_{\mathrm{q}}+1.3 \mathrm{~ms}$ (d) $t_{\mathrm{q}}+2.3 \mathrm{~ms}$. Pressure $=11 \mathrm{kPa}$. 
moval from the crevice is limited by diffusion. Since the dominant mechanism of transport of $\mathrm{CH}_{4}$ out of the crevice is diffusion, and the diffusion coefficient varies as $1 / \rho$, based on this consideration alone the methane should be removed more slowly as the pressure is increased. To test this, a crevice calculation at a terminal pressure of about $25 \mathrm{kPa}$ was performed. As expected, the methane is consumed more slowly than in the lower pressure case of Fig. 9.

The $\mathrm{CH}_{4}$ consumption time after $t_{\mathrm{q}}$ near a flat cooled wall has been shown here and at a pressure of $100 \mathrm{kPa}$ and above [10] to decrease with increasing pressure. At the two pressures for which we have done calculations in the presence of a cooled crevice, the $\mathrm{CH}_{4}$ consumption time shows exactly the opposite trend. Although we hesitate to extrapolate our conclusions to a higher pressure without actually performing the calculaion, our results strongly suggest that a cooled crevice of dimensions comparable to the flame quench distance can have a much greater effect on the residual unburned hydrocarbon concentration in a combustion bomb or an engine than does the laminar quench layer next to a flat, cooled surface.

These conclusions do not apply, of course, if the flame penetrates the crevice. At a high enough pressure the flame can penetrate the crevice, a possibility that was indicated in a previous study [12] to explain the decrease of residual unburned hydrocarbons with increasing pressure in a combustion bomb containing a crevice. According to the results of Friedman and Johnston [20], a methane flame will penetrate a crevice $0.04 \mathrm{~cm}$ across if its single-wall quench distance is 0.016 . The pressure in a burning stoichiometric methane-air mixture with $T_{\text {wall }}=300 \mathrm{~K}$ would have to be greater than $100 \mathrm{~atm}$ for the quench distance to be that small [23]. In the case of methanol the pressure would have to be $70-80$ atm [4].

\section{CONCLUSIONS}

We conclude from these calculations that heterogeneous radical recombination on a cooled surface is of minor importance compared to homogeneous recombination occurring in the cooled flame gases near a surface. It is therefore unlikely that deposits in an engine cylinder can contribute significantly to flame quenching by chemically destroying flame radicals which collide with a deposit-coated surface. The potentially important role of cooled crevices in quenching a flame and hindering oxidation of residual fuel compared to quenching by a cooled flat wall has been quantitatively demonstrated at low pressure. Flame quenching by a cooled crevice is qualitatively different from quenching by a flat wall at the same temperature in that the thickness of the layer of unburned fuel in the crevice case is approximately independent of pressure until a high enough pressure is reached so that the flame is thin enough to penetrate the crevice. Otherwise, the unburned fuel can be removed from the crevice only by diffusion, which slows down as the pressure increases. In the flatwall case, the thickness of this unburned fuel layer decreases with increasing pressure and is burned up faster. These results reaffirm the important role that crevices can play in hindering the complete oxidation of fuel in engines.

\section{REFERENCES}

1. Lund, C. M., UCRL-52504, Lawrence Livermore Laboratory, 1978.

2. Oran, E., Young, T., and Boris, R., Seventeenth Symposium (International) on Combustion. The Combustion Institute, Pittsburgh, 1979, p. 43.

3. Westbrook, C. K., and Dryer, F. L., Eighteenth Symposium (International) on Combustion, The Combustion Institute, Pittsburgh, 1981, p. 749.

4. Westbrook, C. K., and Dryer, F. L., Combust. Sci. Tech. 20:125 (1979) and references cited therein.

5. Westbrook, C. K., Combust. Sci. Tech. 20:5 (1979).

6. Westbrook, C. K., Creighton, J., Lund, C., and Dryer, F. L., J. Phys. Chem. 81:2542 (1977).

7. Adamczyk, A. A., Kaiser, E. W., Cavolowski, J. A., and Lavoie, G. A., Eighteenth Symposium (Interna. tional) on Combustion, The Combustion Institute, Pittsburgh, 1982, p. 1695.

8. Sloane, T. M., and Ratcliffe, J. W., Combust. Flame $47: 83$ (1982).

9. Bechtel, J. H., and Blint, R. J., Appl. Phy's. Lett. 37: 576 (1980).

10. Westbrook, C. K., Adamczyk, A. A., and Lavoie, G. A., Combust. Flame 40:81 (1981).

11. Lorusso, J. A., Kaiser, E. W., and Lavoie, G. A., Combust. Sci. Tech. 25:121 (1981). 
12. Bergner, P., Eberius, H., and Pokorny, H., Proceedings of Third International Symposium on Alcohol Fuels Technology, Asilomar, California, 1979.

13. Wentworth, J. T., Combust. Sci. Tech. 4:97 (1971).

14. Kaiser, E. W., Adamczyk, A. A., and Lavoie, G. A., Eighteenth Symposium (International) on Combus. tion, The Combustion Institute, Pittsburgh, 1981, p. 1881.

15. Carrier, G., Fendell, F., and Feldman, P., Combust. Sci. Tech. 25:9 (1981).

16. Hirschfelder, J. O., Curtiss, C. F., and Bird, R. B., Molecular Theory of Gases and Liquids, Wiley, New York, 1964.

17. Westbrook, C.K., and Chase, L. L., UCID-17833, Lawrence Livermore Laboratory, 1978.
18. Jensen, D. E., and Jones, G. A., Combust. Flame $32: 1$ (1978).

19. Coffee, T. P., and Heimerl, J. M., Combust. Flam 43:273 (1981).

20. Friedman, R., and Johnston, W. C., J. Appl. Phys. 21:791 (1950).

21. PDEPACK: Partial Differential Equations Package Scientific Computing Consulting Services, Livermore California.

22. Roache, P. J., Computational Fluid Dynamics, Hermosa Publishers, Albuquerque, 1972.

23. Tsatsaronis, G., Combust. Flame 33:217 (1978).

Received 19 October 1981; revised 9 June 1982 